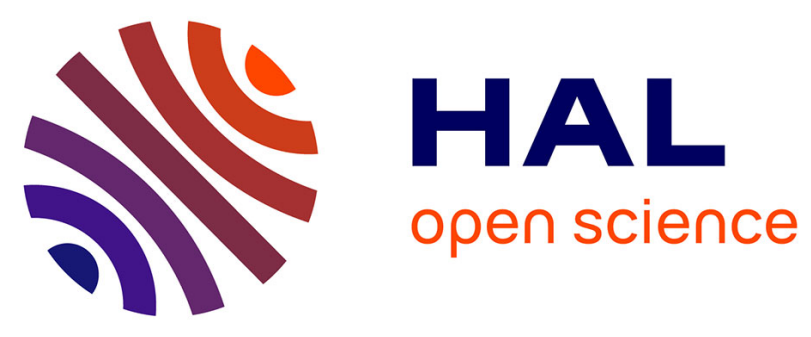

\title{
Three-Component Synthesis of Chromeno $\beta$-Lactam Hybrids for Inflammation and Cancer Screening
} Nassim Borazjani, Saghi Sepehri, Maryam Behzadi, Aliasghar Jarrahpour, Javad Ameri Rad, Maryam Sasanipour, Milad Mohkam, Younes Ghasemi, Amin Reza Akbarizadeh, Carole Digiorgio, et al.

\section{To cite this version:}

Nassim Borazjani, Saghi Sepehri, Maryam Behzadi, Aliasghar Jarrahpour, Javad Ameri Rad, et al.. Three-Component Synthesis of Chromeno $\beta$-Lactam Hybrids for Inflammation and Cancer Screening. European Journal of Medicinal Chemistry, 2019, 179, pp.389-403. 10.1016/j.ejmech.2019.06.036 . hal-02392426

\section{HAL Id: hal-02392426 \\ https://hal-amu.archives-ouvertes.fr/hal-02392426}

Submitted on 4 Dec 2019

HAL is a multi-disciplinary open access archive for the deposit and dissemination of scientific research documents, whether they are published or not. The documents may come from teaching and research institutions in France or abroad, or from public or private research centers.
L'archive ouverte pluridisciplinaire HAL, est destinée au dépôt et à la diffusion de documents scientifiques de niveau recherche, publiés ou non, émanant des établissements d'enseignement et de recherche français ou étrangers, des laboratoires publics ou privés. 


\title{
Three-Component Synthesis of Chromeno $\beta$-Lactam Hybrids for Inflammation and Cancer Screening
}

\author{
Nassim Borazjania ${ }^{\mathrm{a}}$, Aliasghar Jarrahpour ${ }^{\mathrm{a}}$, Saghi Sepehrib ${ }^{\mathrm{b}}$, Maryam Behzadic, Milad \\ Mohkam $^{\mathrm{d}}$, Younes Ghasemic ${ }^{\mathrm{e},}$, Amin Reza Akbarizadeh ${ }^{\mathrm{f}}$ Carole Digiorgio $^{\mathrm{g}}$, Jean Michel \\ Brunel $^{\text {h }}$, Mohammad Mehdi Ghanbari ${ }^{i}$, Gyula Batta ${ }^{i}$, Edward Turos $^{j}$ \\ ${ }^{a}$ Department of Chemistry, College of Sciences, Shiraz University, Shiraz, 71946-84795, Iran. \\ ${ }^{\mathrm{b}}$ Department of Medicinal Chemistry, School of Pharmacy, Ardabil University of Medical Sciences, Ardabil, Iran \\ ${ }^{c}$ Pharmaceutical Research Center, Shiraz University of Medical Sciences, Shiraz, Iran \\ ${ }^{\mathrm{d}}$ Biotechnology Research Center, Shiraz University of Medical Sciences, Shiraz, Iran \\ ${ }^{\mathrm{e}}$ Department of Biotechnology, School of Pharmacy, Shiraz University of Medical Sciences, Shiraz, Iran \\ ${ }^{\mathrm{f}}$ Department of Pharmacology and Toxicology, School of Pharmacy, Shiraz University of Medical Sciences, Shiraz, \\ Iran \\ g Aix Marseille Université, CNRS, IRD, IMBE UMR 7263, Laboratoire de Mutagénèse Environnementale, 13385 \\ Marseille, France.. \\ ${ }^{\mathrm{h}}$ Aix Marseille Univ, INSERM, SSA, MCT, Marseille, France \\ ${ }^{I}$ Department of Chemistry, University of Debrecen, Debrecen, Egyetem tér 1, 4032, Debrecen, Hungary. \\ ${ }^{j}$ Center for Molecular Diversity in Drug Design, Discovery, and Delivery, Department of Chemistry, CHE 205, 4202 \\ East Fowler Avenue, University of South Florida, Tampa, FL 33620, USA.
}

Email address: jarahpor@shirazu.ac.ir; aliasghar6683@yahoo.com

\begin{abstract}
Highly diastereoselective synthesis of chromeno $\beta$-lactam hybrids was achieved by an efficient one-pot three-component reaction. With this procedure, the desired $\beta$-lactam products were obtained in good yields and with exclusive cis stereoselection, by combining a variety of benzaldehydes, malononitrile, and either 5,5-dimethylcyclohexane-1,3-dione or 4hydroxycoumarin in the presence of 1,4-diazabicyclo[2.2.2] octane under reflux conditions. These adducts were structurally characterized on the basis of IR, ${ }^{1} \mathrm{H}$ NMR, ${ }^{13} \mathrm{C}$ NMR spectral data and elemental analysis. Each of the synthesized compounds was screened for anti-inflammatory and anticancer activities. $\beta$-Lactams $\mathbf{5 b}$ and $\mathbf{8 b}$ showed a 53.4 and 19.8 anti-inflammatory ratio, respectively, and $\mathbf{5 b}$ appeared more active than the well-known dexamethasone corticosteroid used for the treatment of rheumatoid and skin inflammation. $\beta$-Lactams $5 \mathbf{5 a}, 5 \mathbf{b}, \mathbf{5 e}, \mathbf{5 f}, \mathbf{5 g}, \mathbf{8 c}, \mathbf{8 j}$ and $\mathbf{8 p}$ also showed good antitumor activity against the SW1116 (colon cancer) cell line without notable cytotoxicity towards the HepG2 control cell line.
\end{abstract}

Keywords: $\beta$-Lactams, tetrahydro- $4 H$-chromene, dihydropyrano[ $[c]$-chromene, one-pot threecomponent synthesis, DABCO, anti-inflammatory, anticancer, colon cancer, cytotoxicity.

\section{Introduction}

In the recent past, our laboratories have pursued research exploring the synthetic combination of several prominent classes of bioactive compounds to create new scaffolds with pharmacological potential. Pharmacophore hybridization has emerged as a paradigm for pharmaceutical chemists. The main motivations for using this strategy are the significant improvement in the therapeutic 
potential, strength, mode of action and pharmacokinetics [1-4]. Multicomponent reactions (MCRs) have recently been exploited as a means to synthesize a variety of chemically-hybridized compounds, including those of interest for biological evaluation. Among the synthetic methods utilized for this purpose, single-pot multi-component reactions provide the most efficient routes to the desired products, avoiding the need to isolate and purify intermediate products while improving atom economy and product yields [5]. Medicinal chemists have further exploited multi-component synthesis in order to construct compounds of pharmaceutical interest, by combining two or more structural subunits units that have their own biological activities. In some cases, these biological activities are complementary to one another or aid in the enrichment of some desired properties, such as antimicrobial activity (bifunctional or even trifunctional prodrugs), or completely orthogonal (such as anticancer with antimicrobial). Recently our laboratories have explored applications of the MCR approach to uncover new chemical structures with intriguing biological properties. In this study, we explore the unique combination of two different classes of bioactive structures, namely fused chromenes and $\beta$-lactams (Figure 1).
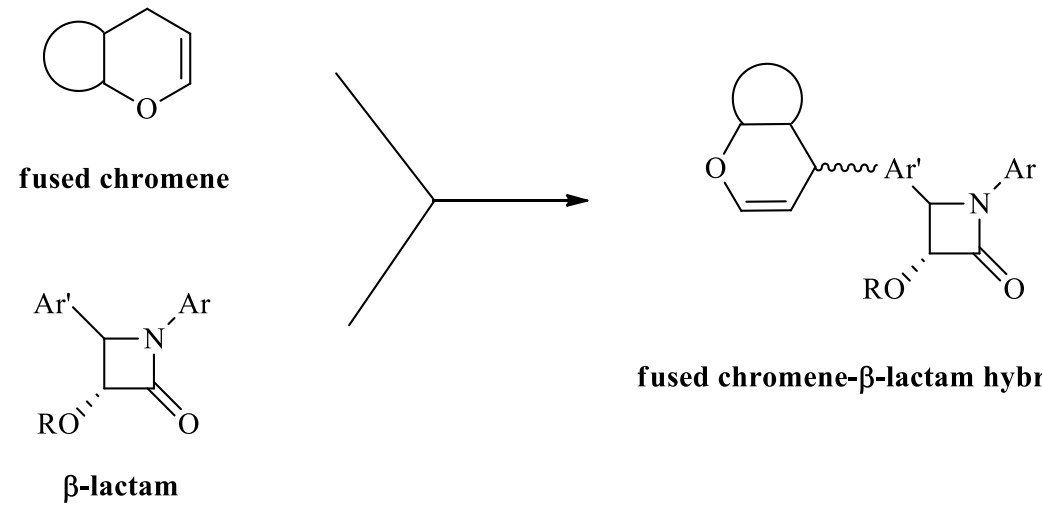

fused chromene- $\beta$-lactam hybrid

Figure 1: Generalized structure of a fused chromene- $\beta$-lactam hybrid.

Tetrahydro- $4 H$-chromenes and dihydropyrano[c]-chromenes have diverse pharmacological potential as anti-allergenic, anti-proliferative, antibacterial, antiviral, antifungal, antioxidant, antitumor, and anticancer agents [6-9]. Examples include benzopyrans $\mathbf{A}$ and $\mathbf{B}$, which possess anticancer activity [10], and compound $\mathbf{C}$, which has antibacterial activity [11] (Figure 2).<smiles>CN(C)c1ccc2c(c1)OC(N)=C(C#N)C2c1ccc(N(C)C)c2ccccc12</smiles>

A<smiles>COc1cc(C2C=C(N)Oc3cc(N(C)C)ccc32)cc(Br)c1OC</smiles>

$\mathbf{B}$<smiles>CC1(C)CC(=O)C2=C(C1)OC(N)=C(C#N)C2[Al]</smiles>

C

Figure 2: Structures of biologically-active fused chromenes. 
The discovery and clinical development of $\beta$-lactam antibiotics remains one of the major advances in modern medicine [12]. The commonly used bicyclic $\beta$-lactam antibiotics such as the penicillins and cephalosporins prevent bacterial transpeptidases from crosslinking the polysaccharide cell wall [13]. More recently, functionalized monocyclic $\beta$-lactams have been developed having a host of other pharmaceutical capabilities, such as anti-HIV [14], antifungal [15], anticancer [16,17] and antimalarial [18] (Figure 3), anti-inflammatory, or analgesic activities [19]. Thus, the $\beta$-lactam framework presents a rich source of diverse biological properties.
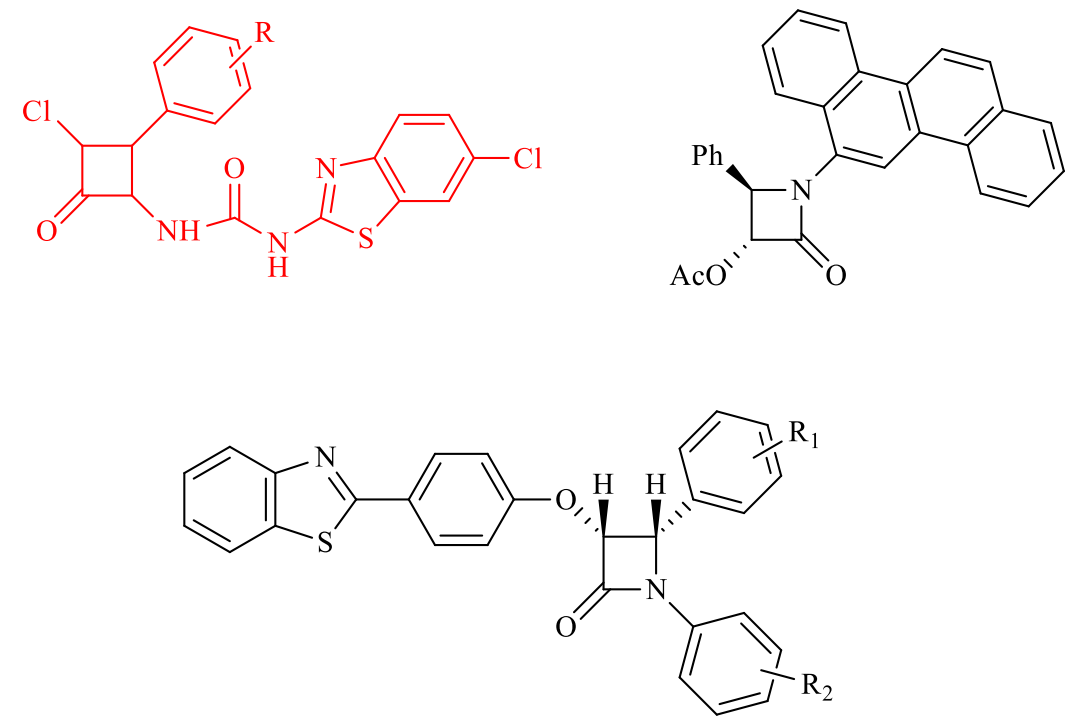

Figure 3: Structures of some biologically active monocyclic $\beta$-lactam derivatives.

In this current study, we set our focus on unique $\beta$-lactams 8a-p bearing tetrahydro- $4 H$ chromene and dihydropyrano[ $[c]$-chromene pharmacophores, through the development of a singlepot, multi-component coupling strategy (Scheme 1).<smiles>O=Cc1ccc(O)cc1</smiles>

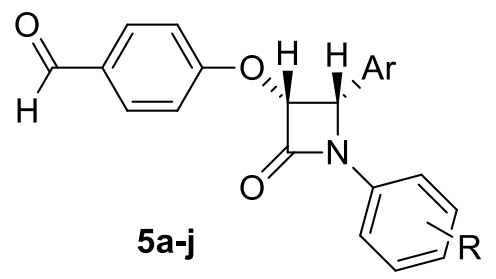<smiles>O=Cc1ccc(OCC(=O)O)cc1</smiles>

3

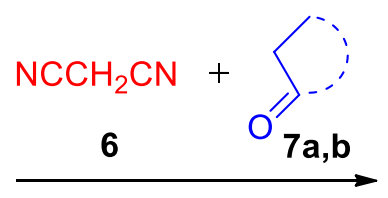

DABCO in refluxing $\mathrm{EtOH}$

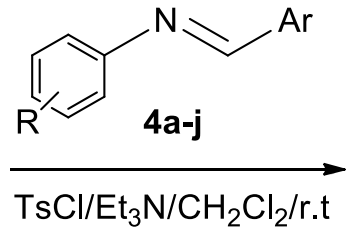<smiles></smiles> 
Scheme 1: Multi-component synthesis of aldehydic $\beta$-lactams 5a-j and chromeno $\beta$-lactam hybrids 8a-p.

\section{Results and discussion}

\subsection{Chemistry}

In this study, $\beta$-lactams $\mathbf{5 a - j}$ were synthesized by a diastereoselective ketene-imine cycloaddition reaction (Scheme 1) [18,20]. The reaction of 4-hydroxybenzaldehyde (1) with bromoacetic acid (2) in DMF at $70^{\circ} \mathrm{C}$ in the presence of solid $\mathrm{K}_{2} \mathrm{CO}_{3}$ afforded 2-(4formylphenoxy)acetic acid (3). Treatment of $\mathbf{3}$ with Schiff bases $\mathbf{4 a - j}$ in the presence of equimolar amounts of triethylamine and p-toluenesulfonyl chloride produced the cis- $\beta$-lactams $\mathbf{5 a - j}$ in isolated yields varying from $68-80 \%$ after column chromatography. Structures were established on the basis of their IR, ${ }^{1} \mathrm{H}$ NMR, ${ }^{13} \mathrm{C}$ NMR spectral data and elemental analysis (see supplementary material). The IR spectra of $\mathbf{5 b}$ showed absorption band at $v 1759 \mathrm{~cm}^{-1}$ for the $\beta$ lactam carbonyl group and absorption band at $v 1689 \mathrm{~cm}^{-1}$ for the aldehyde carbonyl group. Compound $\mathbf{5 b}$ showed doublets at $\delta 5.79 \mathrm{ppm}$ and $\delta 6.03 \mathrm{ppm}$ for the $\mathrm{H}-2$ and $\mathrm{H}-3 \beta$-lactam ring protons. The aldehydic hydrogen resonated as a singlet at $\delta 9.81 \mathrm{ppm}$. The ${ }^{13} \mathrm{C}$ NMR spectral data for compound $\mathbf{5 b}$ exhibited signals at $\delta 60.9$ and $\delta 80.4 \mathrm{ppm}$ for the C-2 and C-3 $\beta$-lactam ring protons, respectively, the aromatic carbons at appropriate shifts, the $\beta$-lactam carbonyl carbon at $\delta$ $161.4 \mathrm{ppm}$ and the aldehyde carbonyl carbon at $\delta 190.5 \mathrm{ppm}$. The cis stereochemistry was confirmed from the vicinal coupling constants of the two $\beta$-lactam ring protons, $\mathrm{H}-2$ and $\mathrm{H}-3\left(\mathrm{~J}_{2,3}\right.$ $\geq 4.0 \mathrm{~Hz}$ ) [18]. X-Ray single crystal analysis done on $\beta$-lactam $\mathbf{5 b}$ confirmed the cis stereochemistry (Fig. 3). Crystallographic data, details of the data collection and structure refinement can be found in the supplementary material [22].

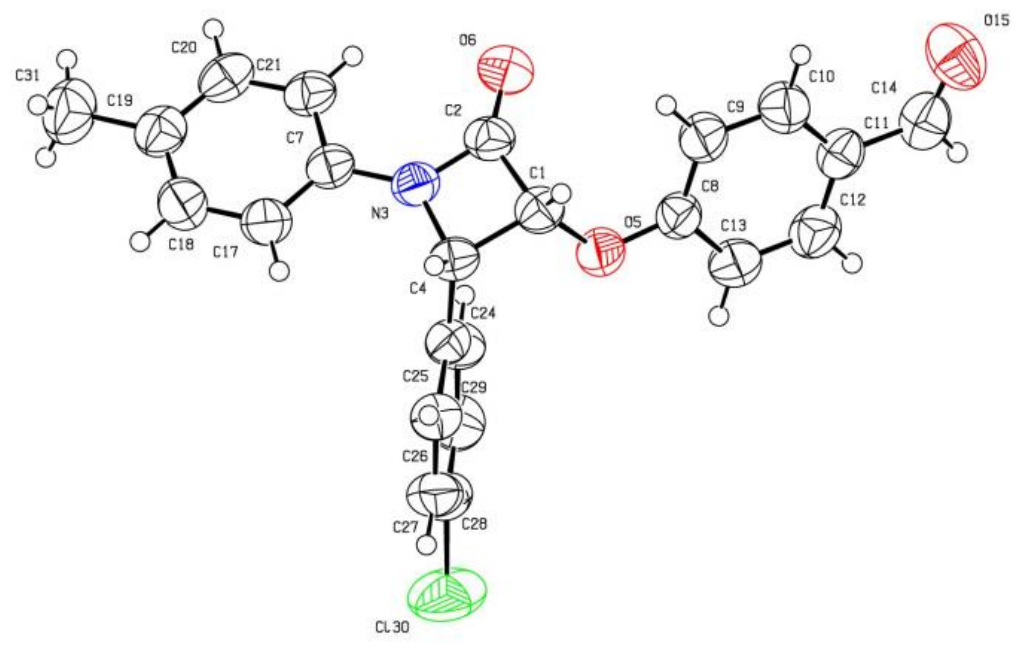

Figure 3: ORTEP diagram of $\beta$-lactam 5b.

From aldehydic $\beta$-lactams $\mathbf{5}$, we further developed an expedient multi-component approach for constructing chromeno $\beta$-lactam hybrids $\mathbf{8}$ (Scheme 2). 
<smiles>[R]c1ccccc1N1C(=O)[C@H](Oc2ccc(C=O)cc2)[C@H]1[14CH3]</smiles><smiles>CC(C)(C)O[Mg]O[Mg]</smiles>

$\mathrm{DABCO}$ in refluxing $\mathrm{EtOH}$
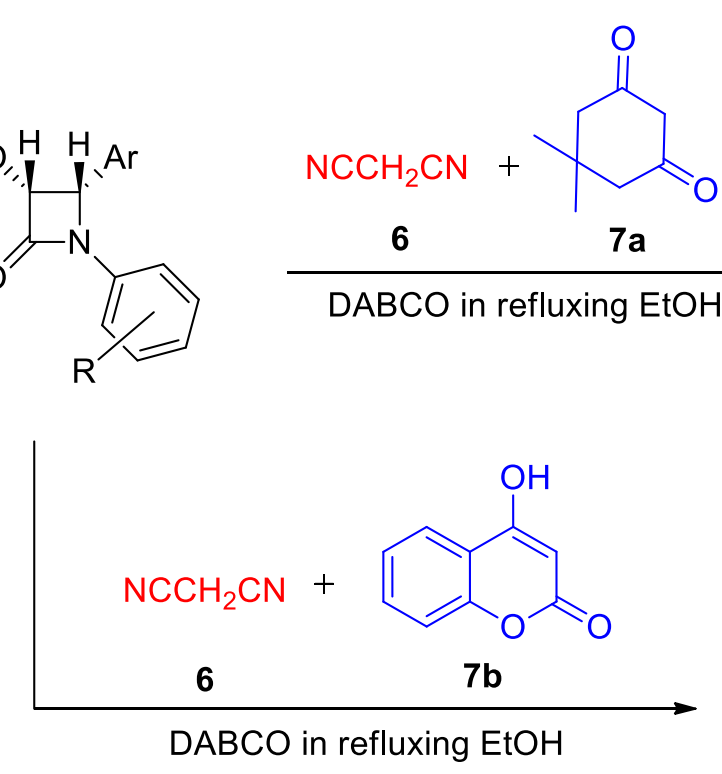
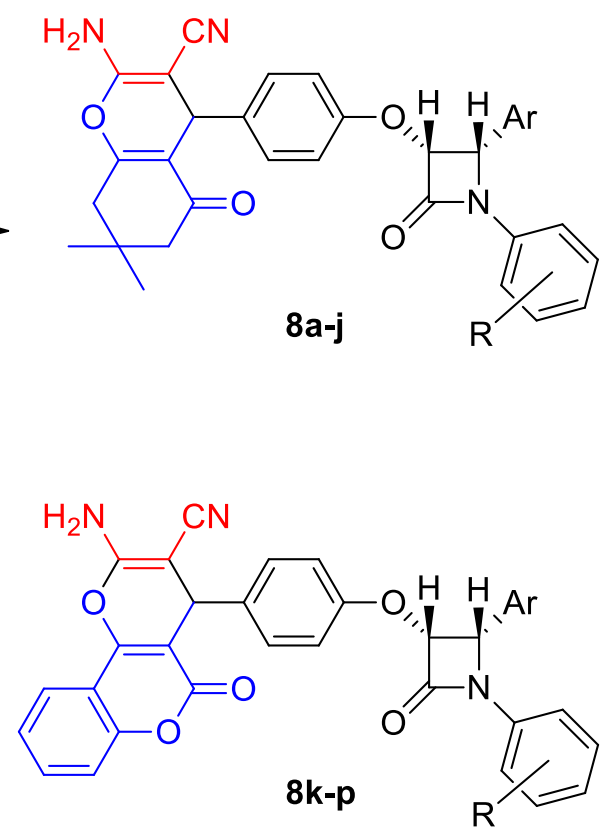

Scheme 2: Multi-component synthesis of chromeno $\beta$-lactam hybrids 8a-p.

To optimize the reaction conditions, $\beta$-lactam 5a was stirred in ethanol with equimolar amounts of malononitrile (6) and 5,5-dimethylcyclohexane-1,3-dione (7a) in the presence of different amine base catalysts (Table 1). A higher yield and shorter reaction time were observed when the reaction was carried out in the presence of a molar equivalent of 1,4-diazabicyclo[2.2.2] octane (DABCO) under reflux conditions (entry 6) [23,24]. 
Table 1. Effects of reagent and solvent on the reaction of $\beta$-lactam 5a, malononitrile (6) and 5,5dimethylcyclohexane-1,3-dione (7a) under different reaction conditions.

\begin{tabular}{|c|c|c|c|c|c|c|}
\hline Entry & Reagent & Reagent (mmol) & Solvent & $\operatorname{Temp}\left({ }^{\circ} \mathrm{C}\right)$ & Time (h) & Yield $^{\mathrm{a}}$ \\
\hline 1 & - & - & $\mathrm{EtOH}$ & Reflux & 48 & - \\
\hline 2 & $\mathrm{Et}_{3} \mathrm{~N}$ & 1.0 & $\mathrm{EtOH}$ & Reflux & 5 & 70 \\
\hline 3 & $\mathrm{~K}_{2} \mathrm{CO}_{3}$ & 1.0 & $\mathrm{EtOH}$ & Reflux & 8 & 62 \\
\hline 4 & DABCO & 0.5 & $\mathrm{EtOH}$ & Reflux & 1.5 & 75 \\
\hline 5 & DABCO & 1.5 & $\mathrm{EtOH}$ & Reflux & 1.5 & 95 \\
\hline 6 & DABCO & 1.0 & EtOH & Reflux & 1.5 & 95 \\
\hline 7 & $\mathrm{DABCO}$ & 1.0 & $\mathrm{MeCN}$ & Reflux & 10 & 20 \\
\hline 8 & DABCO & 1.0 & $\mathrm{H}_{2} \mathrm{O}$ & Reflux & 10 & 50 \\
\hline 9 & DABCO & 1.0 & $\mathrm{MeOH}$ & Reflux & 10 & 55 \\
\hline 10 & DABCO & 1.0 & $\mathrm{CHCl}_{3}$ & Reflux & 10 & Trace \\
\hline 11 & DABCO & 1.0 & EtOAc & Reflux & 10 & 24 \\
\hline 12 & DABCO & 1.0 & $\mathrm{EtOH}$ & r.t. & 8 & 60 \\
\hline 13 & $\mathrm{DABCO}$ & 1.0 & - & 80 & 10 & 33 \\
\hline 14 & DABCO & 1.0 & - & 100 & 10 & 46 \\
\hline
\end{tabular}

assolated yields.

Subsequently, these optimized reaction conditions were used for the condensations of $\beta$-lactams 5a-j (Table 2). 
Table 2. Isolated yields of chromeno $\beta$-lactam hybrids $\mathbf{8}$ under the optimized reaction conditions.

\begin{tabular}{|c|c|c|c|c|c|c|c|c|c|}
\hline Cpd & $\mathbf{R}$ & Ar & $\begin{array}{c}\text { Time } \\
\text { (h) }\end{array}$ & $\begin{array}{c}\text { Yield } \\
(\%)\end{array}$ & Cpd & $\mathbf{R}$ & Ar & $\begin{array}{c}\text { Time } \\
\text { (h) }\end{array}$ & $\begin{array}{c}\text { Yield } \\
(\%)\end{array}$ \\
\hline $8 \mathbf{a}$ & 4-OMe & 4-CIPh & 1.5 & 95 & $8 \mathbf{i}$ & 4-OEt & Anthracene & 1.5 & 92 \\
\hline $8 b$ & 4-Me & 4-CIPh & 2.5 & 90 & $8 \mathbf{j}$ & 4-OMe & Anthracene & 1.5 & 90 \\
\hline $8 c$ & 4-Cl & $3-\mathrm{NO}_{2} \mathrm{Ph}$ & 2.2 & 92 & $8 \mathbf{k}$ & 4-OEt & 4-ClPh & 3.0 & 85 \\
\hline $8 d$ & 4-OMe & 3-NO $\mathrm{N}_{2} \mathrm{Ph}$ & 3.5 & 80 & 81 & 4-OMe & 4-ClPh & 2.6 & 92 \\
\hline $8 e$ & 4-OEt & 4-CIPh & 2.5 & 94 & $8 \mathrm{~m}$ & $4-\mathrm{N}(\mathrm{Me})_{2}$ & $4-\mathrm{NO}_{2} \mathrm{Ph}$ & 4.0 & 82 \\
\hline $8 f$ & 4-OEt & $4-\mathrm{NO}_{2} \mathrm{Ph}$ & 1.6 & 95 & $8 n$ & 4-OEt & $4-\mathrm{N}(\mathrm{Me})_{2} \mathrm{Ph}$ & 3.8 & 90 \\
\hline $8 g$ & 4-N(Me $)_{2}$ & $4-\mathrm{NO}_{2} \mathrm{Ph}$ & 3.2 & 85 & 80 & 4-OEt & Anthracene & 1.8 & 95 \\
\hline $8 \mathrm{~h}$ & 4-OEt & $4-\mathrm{N}(\mathrm{Me})_{2} \mathbf{P h}$ & 3.0 & 90 & $8 p$ & 4-OMe & Anthracene & 2.0 & 90 \\
\hline
\end{tabular}

The cycloadducts were characterized by spectral analysis. The IR spectra of $\mathbf{8 b}$ showed the $\mathrm{NH}_{2}$ stretching vibration at 3386 and $3325 \mathrm{~cm}^{-1}$, the $\mathrm{CN}$ stretching at $2198 \mathrm{~cm}^{-1}$, and the $\beta$-lactam carbonyl at $1743 \mathrm{~cm}^{-1}$. We also noted the absence of the aldehyde carbonyl group at $1689 \mathrm{~cm}^{-1}$, and the appearance of a sharp band at $1666 \mathrm{~cm}^{-1}$ for the vinylogous carbonyl (ketone or lactone). The ${ }^{1} \mathrm{H}$ NMR spectrum for $\mathbf{8 b}$ showed a signal at $\delta 4.07[1 \mathrm{H}, \mathrm{s}, \mathrm{CH}-4]$, doublets at $\delta 5.69[1 \mathrm{H}, \mathrm{d}$, $J=5.0 \mathrm{~Hz}, \mathrm{H}-2$ of $\beta$-lactam] and $\delta 5.82\left[1 \mathrm{H}, \mathrm{d}, J=5 \mathrm{~Hz}, \mathrm{H}-3\right.$ of $\beta$-lactam] and $\mathrm{NH}_{2}$ protons in the aromatic region. These $\mathrm{NH}_{2}$ protons were deuterium-exchanged with $\mathrm{D}_{2} \mathrm{O}$ and the integration of $4 \mathrm{Hs}$ in the region of $\delta 6.88-6.95\left(\mathrm{~m}, \mathrm{ArH}, \mathrm{NH}_{2}\right)$ decreased to $2 \mathrm{H}$, producing a sharp doublet at $\delta$ $6.94(J=10.0 \mathrm{~Hz})$. The ${ }^{13} \mathrm{C}$ NMR spectral data for compound $\mathbf{8 b}$ exhibited aliphatic carbons and aromatic carbons at appropriate shifts, and the ketone carbonyl carbon at $\delta$ 195.9.

\subsection{Anti-inflammatory activity assay}

Inflammation contributes to the degenerative processes of host of human ailments and diseases, such as cancer, arthritis, atherosclerosis, autoimmune diseases and aging of skin and other tissues and organs. Treatment with anti-inflammatory compounds may reduce the severity of inflammation. Non-steroidal anti-inflammatory drugs (NSAIDs) are the most popular pharmaceutical agents for the treatment of chronic inflammatory diseases, pain and fever that exert their therapeutic effect via blockade of cyclooxygenase isoenzymes (arachidonic acid pathway) to prevent the production of prostaglandins and other inflammatory mediators [24]. Nitric oxide (NO) plays significant roles in the pathophysiology of inflammatory illnesses. It gives an antiinflammatory effect under normal physiological conditions. NO is synthesized and released into the endothelial cells by the help of nitric oxide synthases that convert arginine into citrulline producing $\mathrm{NO}$ in the process. Also, $\mathrm{NO}$ is considered as a pro-inflammatory mediator that induces inflammation because of over production in abnormal situations. Therefore, NO inhibitors represent important therapeutic advance in the management of inflammatory diseases [25]. In 
order to identify new anti-inflammatory candidates, the RAW 264.7 murine macrophage assay was used to examine anti-inflammatory behavior of the new $\beta$-lactam hybrids we synthesized. This assay monitors the inflammatory cascade leading to an overproduction of NO in the endothelial lining of blood vessels. In the present study, it was performed to evaluate the capacity of the compounds to inhibit the pro-inflammatory cascade leading to NO production in mouse macrophages. Results are reported in Table 3. Compound $\mathbf{8 b}$ was the most active of all the chromeno $\beta$-lactam hybrids tested, with a 19.8 anti-inflammatory ratio.

Table 3. Anti-inflammatory activity of chromeno $\beta$-lactam hybrids 8a-p.

\begin{tabular}{|c|c|c|c|}
\hline Sample & $\begin{array}{c}\text { IC50-NO release } \\
\text { Sample }(\boldsymbol{\mu M})\end{array}$ & $\begin{array}{c}\text { IC50-cell viability } \\
\text { Sample }(\boldsymbol{\mu M})\end{array}$ & $\begin{array}{c}\text { Anti- } \\
\text { inflammatory } \\
\text { ratio }\end{array}$ \\
\hline $\mathbf{8 a}$ & $\mathrm{ND}$ & $\mathrm{ND}$ & ND \\
\hline $\mathbf{8 b}$ & $6.24 \pm 1.28$ & $123.47 \pm 13.24$ & 19.8 \\
\hline $\mathbf{8 c}$ & $53.41 \pm 5.13$ & $124.21 \pm 8.23$ & 2.3 \\
\hline $\mathbf{8 d}$ & $100.02 \pm 6.21$ & $114.31 \pm 10.31$ & 1.1 \\
\hline $\mathbf{8 e}$ & $73.36 \pm 7.94$ & $201.45 \pm 11.56$ & 2.7 \\
\hline $\mathbf{8 f}$ & $89.42 \pm 6.81$ & $124.31 \pm 11.39$ & 4.4 \\
\hline $\mathbf{8 g}$ & $60.08 \pm 5.24$ & $251.48 \pm 8.37$ & 3.8 \\
\hline $\mathbf{8 h}$ & $38.10 \pm 4.31$ & $146.25 \pm 7.23$ & 1.6 \\
\hline $\mathbf{8 i}$ & $101.65 \pm 23.24$ & $165.23 \pm 10.87$ & 2.4 \\
\hline $\mathbf{8 j}$ & $56.41 \pm 5.64$ & $134.63 \pm 8.24$ & $\mathrm{ND}$ \\
\hline $\mathbf{8 k}$ & $\mathrm{ND}$ & $\mathrm{ND}$ & 1.4 \\
\hline $\mathbf{8 1}$ & $89.56 \pm 3.81$ & $124.31 \pm 8.33$ & $\mathrm{ND}$ \\
\hline $\mathbf{8 m}$ & $161.36 \pm 21.54$ & $163.24 \pm 11.42$ & 1.3 \\
\hline $\mathbf{8 n}$ & $\mathrm{ND}$ & $\mathrm{ND}$ & 1.2 \\
\hline $\mathbf{8 0}$ & $168.23 \pm 11.41$ & $198.56 \pm 12.09$ & 31.9 \\
\hline $\mathbf{8 p}$ & $164.57 \pm 8.84$ & $159.2 \pm 26.35 \mu \mathrm{M}$ & \\
\hline Dexamethasone & $5.02 \pm 1.34 \mu \mathrm{M}$ & & \\
\hline
\end{tabular}

ND : Not determined due to poor solubility

For comparison, we also checked anti-inflammatory activity for the aldehydic $\beta$-lactams 5a-j (Table 4). As observed for lactam $\mathbf{8 b}$, the $p$-tolyl group on $\mathrm{N}$-1 of the $\beta$-lactam ring of $\mathbf{5 b}$ enhances anti-inflammatory activity in this assay, more active than the corticosteroid drug, dexamethasone.

Table 4. Anti-inflammatory activity of derivatives 5a-j.

\begin{tabular}{|c|c|c|c|}
\hline Sample & $\begin{array}{c}\text { IC50-NO release } \\
\text { Sample }(\boldsymbol{\mu M}\end{array}$ & $\begin{array}{c}\text { IC50-cell viability } \\
\text { Sample }(\boldsymbol{\mu M}\end{array}$ & $\begin{array}{c}\text { Anti- } \\
\text { inflammatory } \\
\text { ratio }\end{array}$ \\
\hline $\mathbf{5 a}$ & $92.42 \pm 6.81$ & $131.31 \pm 9.39$ & 1.4 \\
\hline $\mathbf{5 b}$ & $2.31 \pm 0.56$ & $123.78 \pm 7.49$ & 53.4 \\
\hline $\mathbf{5 c}$ & $63.65 \pm 4.07$ & $132.48 \pm 6.37$ & 2.1 \\
\hline $\mathbf{5 d}$ & $2.91 \pm 0.84$ & $4.15 \pm 1.66$ & 1.4 \\
\hline $\mathbf{5 e}$ & $11.32 \pm 0.89$ & $56.28 \pm 6.31$ & 4.9 \\
\hline
\end{tabular}




\begin{tabular}{|c|c|c|c|}
\hline $\mathbf{5 f}$ & $97.73 \pm 9.95$ & $189.65 \pm 8.18$ & 1.9 \\
\hline $\mathbf{5 g}$ & $32.86 \pm 3.35$ & $116.84 \pm 14.58$ & 3.6 \\
\hline $\mathbf{5 h}$ & $125.20 \pm 8.15$ & $241.78 \pm 11.42$ & 1.9 \\
\hline $\mathbf{5 i}$ & $42.58 \pm 4.27$ & $112.56 \pm 10.36$ & 2.6 \\
\hline $\mathbf{5 j}$ & $69.11 \pm 19.45$ & $68.32 \pm 6.87$ & 1.0 \\
\hline
\end{tabular}

\subsection{Anticancer activity and cytotoxicity assays}

In vitro cytotoxicity and anti-cancer activity were also evaluated for each of the compounds synthesized. Three of the chromeno $\beta$-lactam hybrid compounds $(\mathbf{8 c}, \mathbf{8 j}$ and $\mathbf{8 p}$ ) showed elevated anti-cancer activity against the SW 1116 (colon cancer) cell lines, with $\mathrm{IC}_{50}$ values of 7.29, 8.83, and $7.43 \mu \mathrm{M}$, respectively, in comparison to the anticancer agent methotrexate (IC 50 of $2.49 \mu \mathrm{M})$. The remainder of the lactams $\mathbf{8}$ afford no anticancer activity at or below $200 \mu \mathrm{M}$. Since all of these lactams carry a tetrahydro- $4 H$-chromene or dihydropyrano[c]-chromene group on $\mathrm{C}-3$ of the $\beta$ lactam ring, the aryl substituents at $\mathrm{N}-1$ and $\mathrm{C}-2$ of the $\beta$-lactam ring are responsible for these differences in activity. A tentative structure-activity relationship exists, in that the presence of a $p$ nitrophenyl or $p$-chlorophenyl group on $\mathrm{C}$ - 2 of the $\beta$-lactam ring and a $p$-methoxyphenyl, $p$-tolyl, $p$-ethoxyphenyl or $p$ - $N, N$-dimethylaminophenyl ring on $\mathrm{N}-1$ of the $\beta$-lactam provide the best anticancer bioactivity. Additionally, five of the aldehydic $\beta$-lactams $(\mathbf{5 a}, \mathbf{5} \mathbf{b}, \mathbf{5 e}, \mathbf{5 f}$ and $\mathbf{5 g})$ possess comparable $\mathrm{IC}_{50}$ values. $\mathrm{IC}_{50}$ values are $10.26,10.00,6.71,8.19$, and $6.93 \mu \mathrm{M}$, respectively. Conversely, none of the lactams (5a-j or $\mathbf{8 a - p}$ ) have cytotoxicity against HepG2 cells, with $\mathrm{IC}_{50}$ concentrations not being found at or below $200 \mu \mathrm{M}$.

\subsection{Molecular docking studies}

\subsubsection{Validation of molecular docking}

The performance of a common computational docking technique can be tested by checking its power to foresee the most significant binding mode of a cognate (co-crystallographic) ligand [41]. This method was carried out by eliminating the structure of a cognate ligand and re-docking it into its protein (self-docking). Root-mean-square deviation (RMSD) of the Cartesian coordinates of the atoms of the ligand in the docked and crystallographic conformations is the principle of the docking validation (RMSD $<2 \AA$ ). Validation of molecular docking showed RMSD values were for PDB ID: 4NOS = $0.4 \AA$ and for PDB ID: $3 \mathrm{LN} 1=0.01 \AA$ (Supplementary Information).

\subsubsection{Study of the binding mode}

Molecular docking experiments suggest that chromeno $\beta$-lactams 8a-p may bind to human inducible nitric oxide synthase protein via hydrogen bond and hydrophobic interactions with specific active site amino acid residues. Members of this group exhibit weak to good (in the case of 8b) in vitro anti-inflammatory activity, such that higher lipophilicity enhances these particular hydrophobic interactions. Indeed, 8b exhibited the best docking score from the computational studies, coinciding with the most potent in vitro anti-inflammatory activity. Interactions of $\mathbf{8 b}$ with the enzyme active site are depicted in Figure 4. The carbonyl and 4-oxyphenyl oxygen atoms interact through hydrogen bonds with Arg381 (O...NH, $1.96 \AA$ and O...NH, $1.98 \AA$ ). Also the amine nitrogen atom of the $\mathrm{C}-2$ chromeno moiety is involved in a hydrogen bond with Asp382 amino acid (NH...O, $1.96 \AA$ ). Compound $\mathbf{8 b}$ was found to also interact with a hydrophobic surface 
formed by Gln263, Val352, Glu377, Arg388, Trp463, Met120, Pro467, Ile462, Pro466 and Val465 residues.
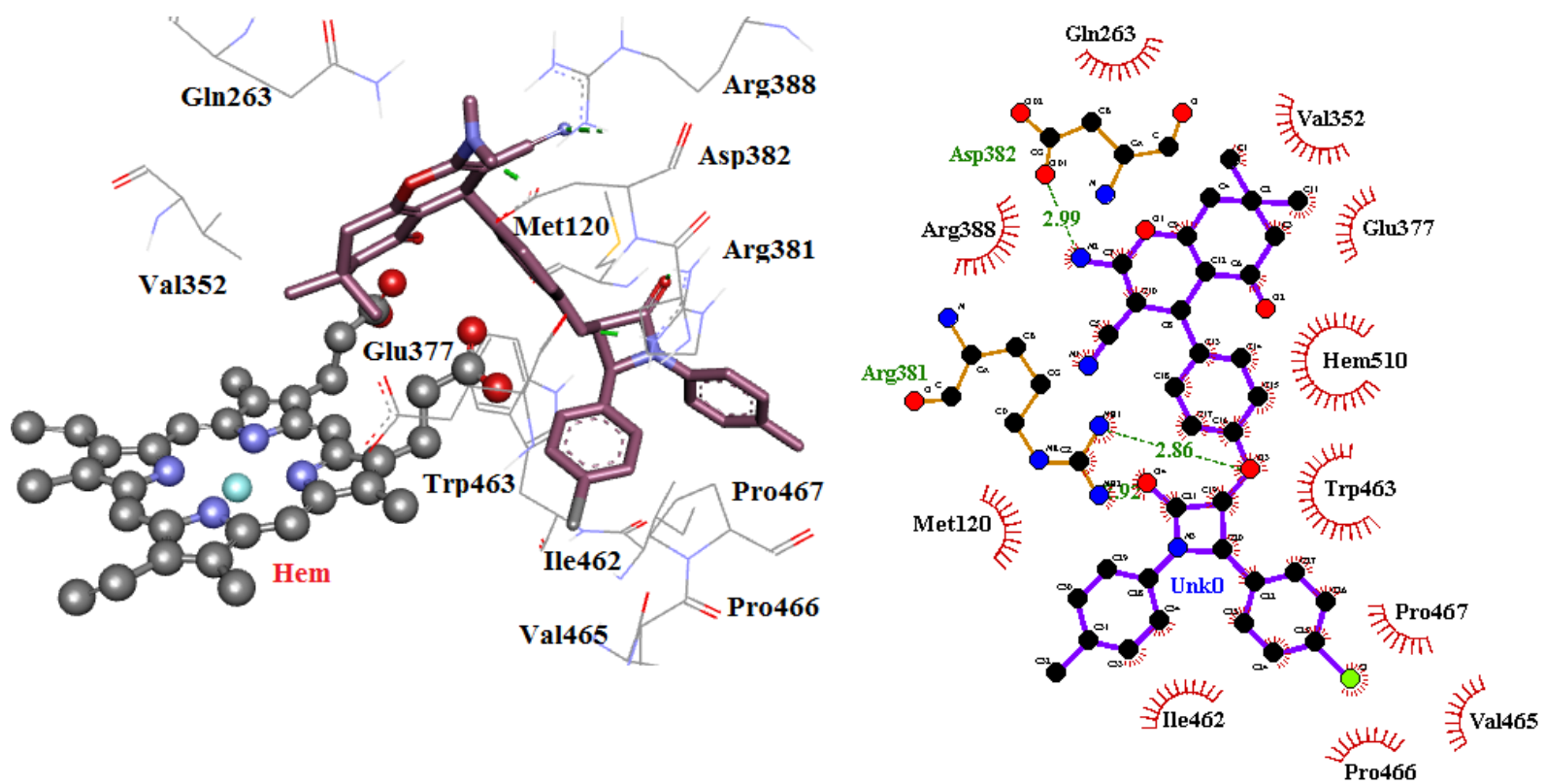

Figure 4: Compound $\mathbf{8 b}$ in the human inducible nitric oxide synthase active site. The 3D (left) and 2D (right) ligand interaction diagrams.

Replacement of the $p$-chlorophenyl group at $\mathrm{C}-4$ position of the lactam ring in $\mathbf{8 e}$ with a $p$ nitrophenyl in $\mathbf{8 f}$ substantially decreased the in vitro activity. The calculated CLogP value for $8 \mathbf{e}$ (6.75) indicates that it is somewhat more lipophilic than $8 \mathbf{f f}(\mathrm{C} \log \mathrm{P}=5.78)$ and can thus experience stronger interactions with hydrophobic amino acids, accounting for its better antiinflammatory activity and free binding energy (Table 4, in Supplementary Information).

Replacing the $p$-( $N, N$-dimethylamino)phenyl ring of $\mathbf{8 h}$ with an anthracene moiety at the C-4 position (8i) decreased the in vitro activity. The lower anti-inflammatory activity of $\mathbf{8 i}$ can be attributed to steric hindrance and a change in the orientation of compound $8 \mathbf{i}$ in the active site, which weakens the intermolecular interactions.

The higher lipophilicity of compound $8 \mathbf{m}(\mathrm{CLogP}=6.51)$ compared with $8 \mathrm{~g}(\mathrm{C} \log \mathrm{P}=5.50)$ likely diminishes cell membrane permeability, causing lower anti-inflammatory activity.

Dexamethasone was likewise computationally docked into the protein and showed a very similar binding mode to the $\beta$-lactams, forming hydrogen bonds and hydrophobic interactions with (Figure 5). 


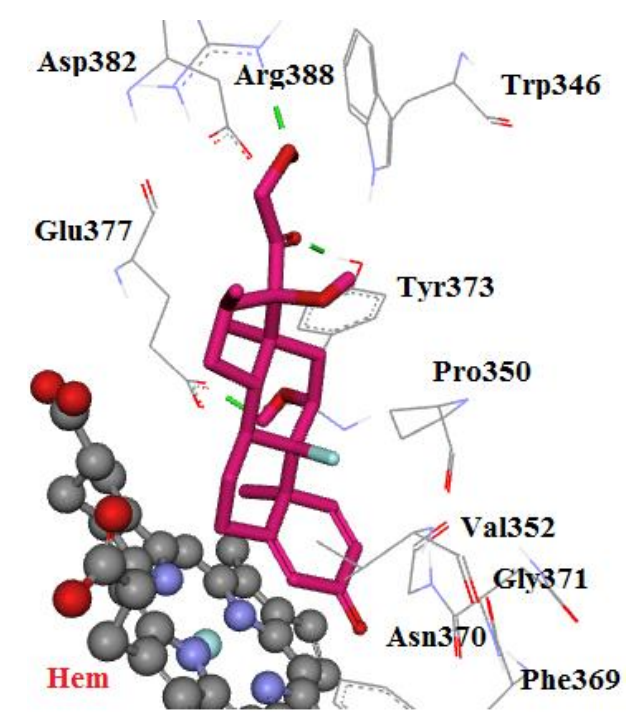

Figure 5: Hydrogen bonds and hydrophobic interactions of dexamethasone within the human inducible nitric oxide synthase active site.

For comparison, we also examined the docking of aldehydic $\beta$-lactams 5 into the human inducible nitric oxide synthase active site. Compounds $\mathbf{5 b}$ and $\mathbf{5 e}$ gave the best docking scores (Table 4, in supporting information) that correspond with their strong anti-inflammatory activity (Table 2). The carbonyl oxygen atom of lactam ring of $\mathbf{5 b}$ formed a hydrogen bond interaction with $\mathrm{NH}$ of Gln263 (O...HN, $1.84 \AA$ ). Moreover, 5e formed two hydrogen bonds with amino acid active sites. The carbonyl oxygen atom of lactam ring displayed a hydrogen bond with $\mathrm{OH}$ group of Tyr373 (O...HO, $2.59 \AA$ ) and the carbonyl oxygen atom of aldehyde showed a hydrogen bond with NH group of $\operatorname{Arg} 388$ (O...HN, $2.18 \AA$ ). The binding mode of compounds $\mathbf{5 b}$ and $\mathbf{5 e}$ to the human inducible nitric oxide synthase active site is revealed in Figure 6
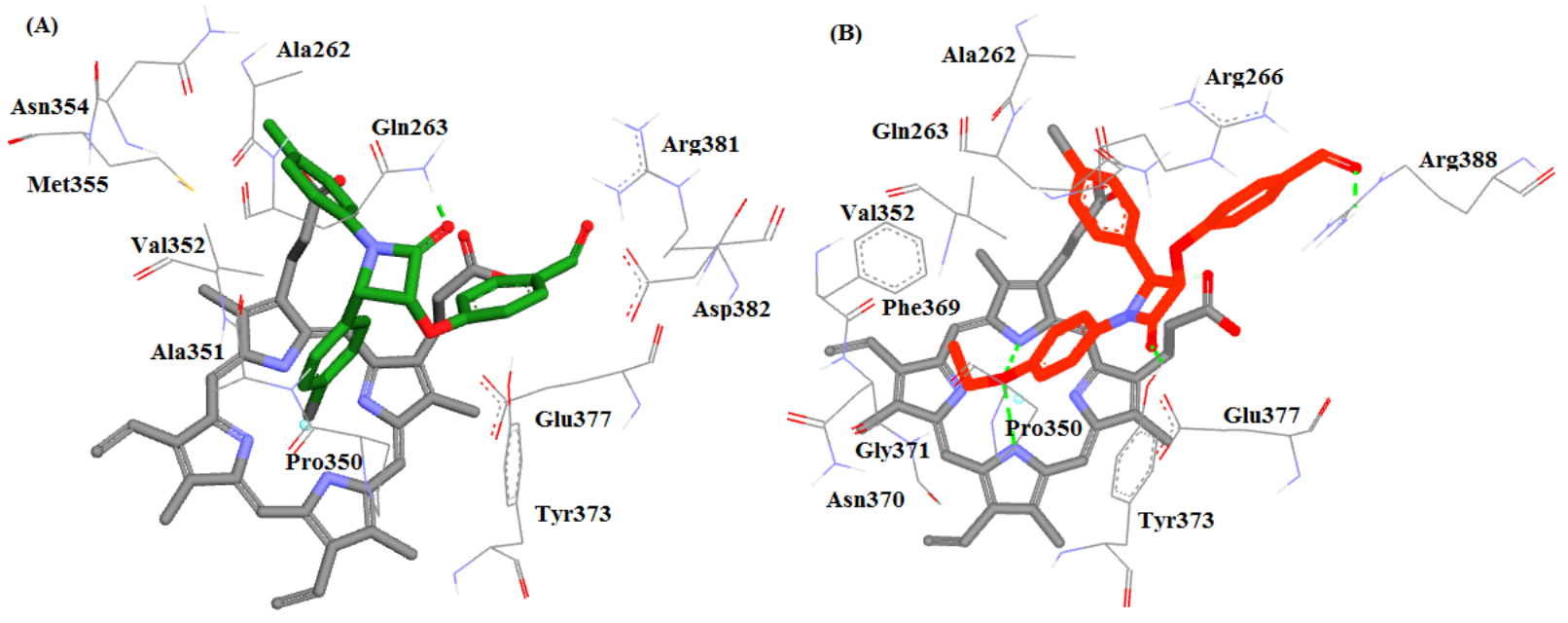
Figure 6: Binding modes of compound $\mathbf{5 b}(\mathbf{A})$ and $\mathbf{5 e}(\mathbf{B})$ with human inducible nitric oxide synthase active site (PDB ID: 4NOS).

The three aryl rings of $\mathbf{5 b}$ were located within the hydrophobic pocket enclosed by Ala351, Asp382, Arg381, Glu377, Tyr373, Pro350, Ala262, Val352, Met355 and Asn354. Exposed residues Arg266, Arg388, Ala262, Val352, Gln263, Pro350, Gly371, Asn370, Glu377 and Phe369 also formed hydrophobic interactions with 5e. Our docking calculations revealed that $\mathbf{5 e}$ forms a cation- $\pi$ interaction with the Arg266 residue. All these interactions help anchor $\mathbf{5 b}$ and $\mathbf{5 e}$ in the binding site of the human inducible nitric oxide synthase protein. In addition, anti-inflammatory activity of $\mathbf{5 b}$ was higher than that of the clinically-used anti-inflammatory agent, dexamethasone $\left(\mathrm{IC}_{50-\mathrm{NO}}\right.$ release $\left.=5.02 \mu \mathrm{M}\right)$.

Replacing the 4-chlorophenyl ring (5e) with the 4-nitrophenyl ring (5f) and 4- $(N, N-$ dimethylamino)phenyl ring (5h) decreased the anti-inflammatory activity. The increased polarization and strong electron-donating characters reduced the potency of compounds but addition of hydrophobic groups had a positive effect. Also, docking results exposed that compounds 5e and $\mathbf{5 f}$ formed a cation- $\pi$ and $\pi-\pi$ stacking interactions with Arg266 and Tyr491 amino acids, respectively. While compound $\mathbf{5 h}$ did not participate in these contacts (Figure 7).

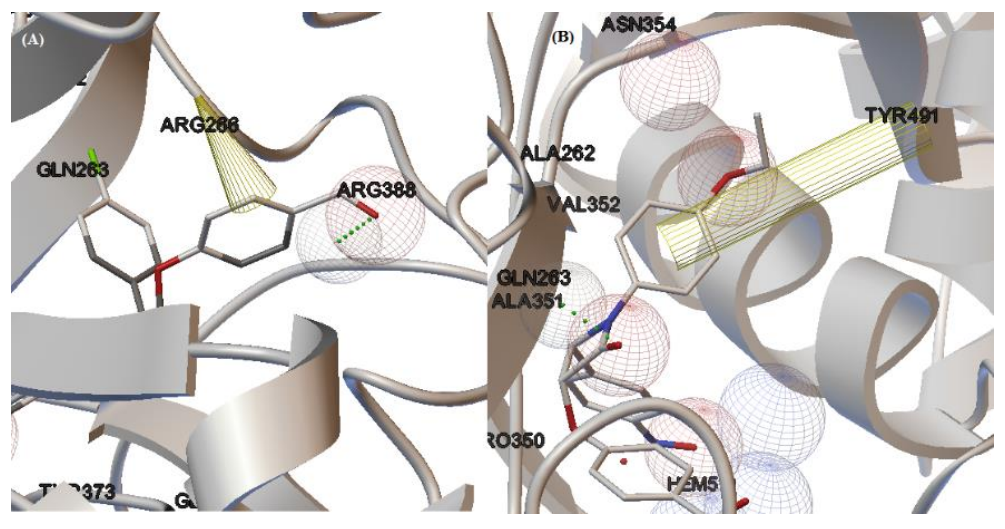

Figure 7: Close up of the calculated binding of $\mathbf{5 e}(\mathbf{A})$ and $\mathbf{5 f}(\mathbf{B})$ within the human inducible nitric oxide synthase enzyme active site.

A methoxy or methyl group at the para position of the aryl ring induced different conformations, leading to a change in interactions with the hydrophobic pocket of the protein. This suggests this is the reason for compound $\mathbf{5} \mathbf{b}$ showing higher anti-inflammatory activity and $\Delta \mathrm{G}_{\text {bind }}$ value than compound 5a. In addition, the carbonyl oxygen atom of lactam ring of $\mathbf{5} \mathbf{b}$ formed a hydrogen bond interaction with NH of Gln263 (O...HN, $1.84 \AA$ ), whereas 5a did not have this interaction. The superimposition of $\mathbf{5 a}$ and $\mathbf{5 b}$ in the enzyme binding site is illustrated in Figure 8. 


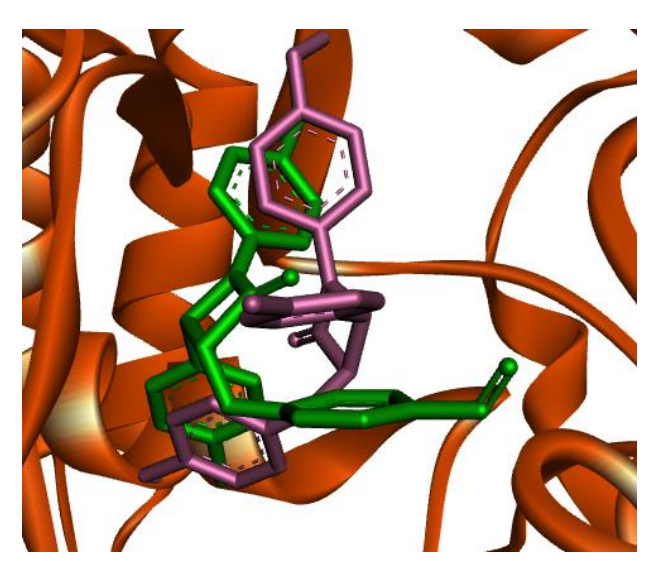

Figure 8: Superimposition of $\mathbf{5 a}$ (violet) and $\mathbf{5 b}$ (green) within the enzyme binding site.

Compound 5a, having a methoxy group at the para position of the aryl ring, showed lower inhibitory activity than compound $\mathbf{5 e}$ that has an ethoxy group at the same position (Table 2). The lower anti-inflammatory activity of $\mathbf{5} \mathbf{a}$ can be attributed to the improper geometric orientation in the active site of enzyme. Also, compound 5e shows two hydrogen bonds with Arg 388 and Tyr373 residues and a cation- $\pi$ stacking interaction with $\operatorname{Arg} 266$, while compound 5a did not have these interactions (Figure 9). Our docking calculations indicate that 5e has stronger interactions than 5a with active site amino acids, accounting for its elevated anti-inflammatory activity.

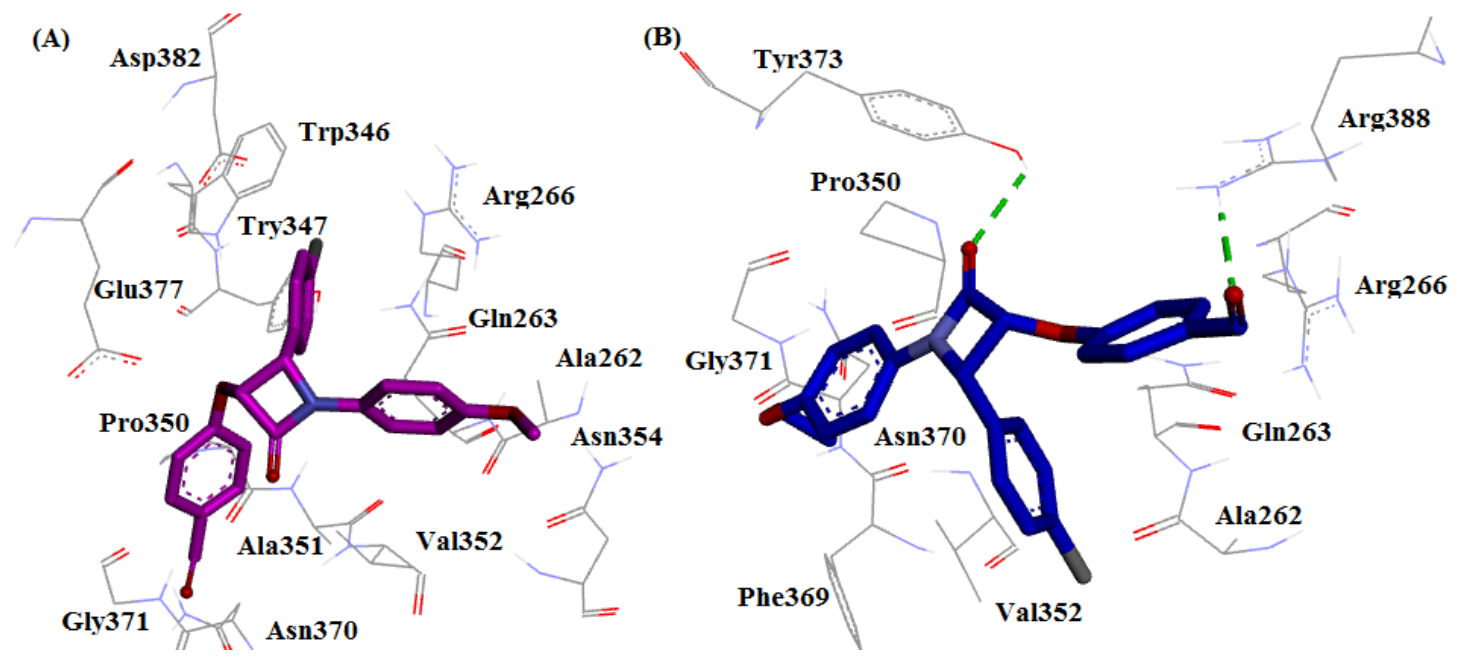

Figure 9: Calculated binding modes of compound 5a (A) and 5e (B) within the human inducible nitric oxide synthase active site (PDB ID: 4NOS).

It is also interesting to compare $\beta$-lactam 5e with $\mathbf{5 i}$. While $\mathbf{5 e}$ has a $p$-chlorophenyl ring at the C-2 position of lactam ring, $\mathbf{5 i}$ has a bulkier anthracene moiety (Figure 10). The computational modeling suggest that steric differences between these two aryl groups, along with the differences in the calculated $\Delta \mathrm{G}_{\text {bind }}$ values for lactams $\mathbf{5 e}$ and $\mathbf{5 i}$, may account for the different antiinflammatory potencies. Moreover, lactam 5e is less hydrophobic than compound $\mathbf{5 i}(\mathrm{CLogP}=$ 5.82 for $5 \mathbf{e} v s$. CLogP $=7.45$ for 5i) and may have reduced permeability through the cell membrane. 


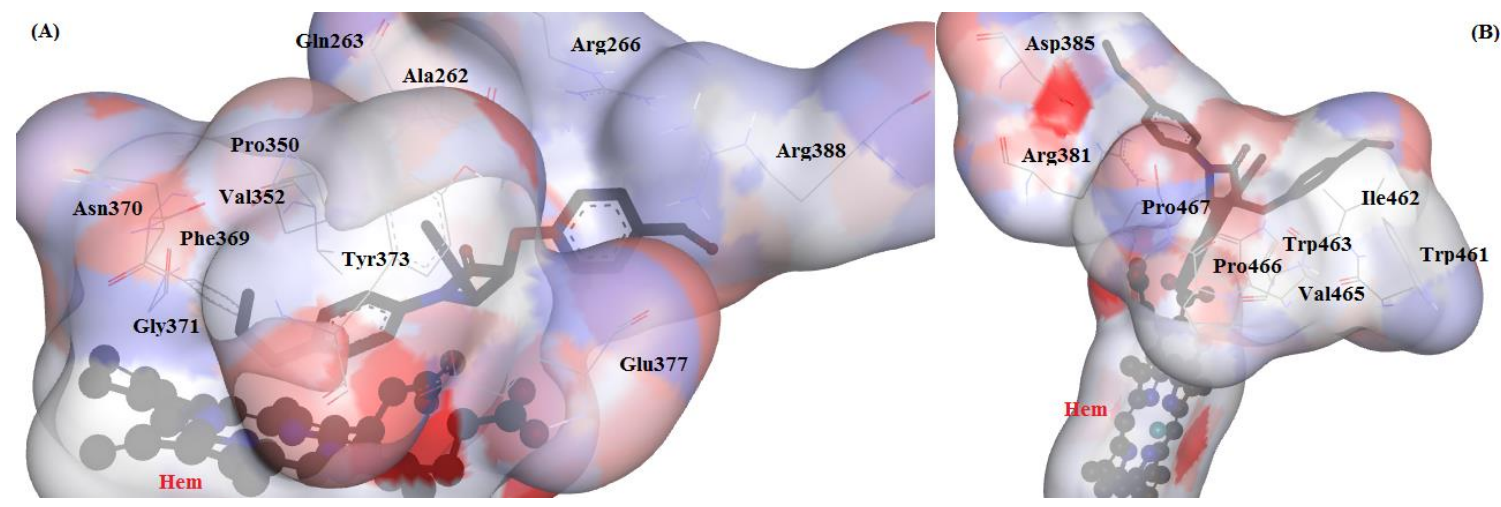

Figure 10: Calculated binding mode of compound 5e (A) and 5i (B) within the human inducible nitric oxide synthase active site (PDB ID: 4NOS

Replacing the $\mathrm{N}$-aryl ethoxy substituent (5f) with an $\mathrm{N}, \mathrm{N}$-dimethylamino (5g) increased antiinflammatory activity, suggesting that increased electron-donation into the $\mathrm{N}$-aryl ring improves potency. This is corroborated by computational docking experiments showing that while compound $\mathbf{5 f}$ forms looser hydrogen bonds with Tyr373 and Arg388, compound $\mathbf{5 g}$ forms a tighter hydrogen bond to the Cys110 residue in the enzyme binding pocket.

\section{Conclusion}

This article describes the first diastereoselective synthesis of chromeno-substituted $\beta$-lactams. The compounds were accessed by an expedient single-pot three-component synthesis approach, to give exclusively the cis-disubstituted adducts. The series of chromeno $\beta$-lactam hybrids 8a-p, as well as their aldehydic precursors $\mathbf{5 a - j}$, were evaluated for anti-inflammatory activity. The best anti-inflammatory activity was observed for compounds 5b and 8b (53.4 and 19.8 antiinflammatory ratio, respectively). Moreover, based on the results of anti-inflammatory activity and molecular docking calculations of the synthesized compounds, the anti-inflammatory activity is closely dependent on the substituents at the N1 and C-2 centers of the lactam ring. Chromeno lactams 8c, 8j and 8p, as well as aldehydic lactams 5a, 5b, 5e, 5f, 5g, display in vitro anticancer activity against the SW 1116 colon cancer cell line, without noticeable cytotoxicity towards healthy cells. Studies are now underway to improve the biological activity and determine the mechanism of action.

\section{Conflict of interest}

The authors declare that they have no conflict of interest.

\section{Acknowledgements}


The authors would like to thank the Shiraz University Research Council for financial support (Grant No. 97-GR-SC-23) and Dr. Attila Benyei for collecting X-ray data.

\section{Appendix A. Supplementary data}

Electronic Supplementary Information (ESI) available: Spectra for new compounds (IR, ${ }^{1} \mathrm{H}$ NMR, ${ }^{13} \mathrm{C}$ NMR spectral data), elemental analysis, molecular docking studies data, crystallographic data and structure determination and General experimental methods.

\section{References}

[1] J. R. Morphy, Z. Rankovic, The physicochemical challenges of designing multiple ligands, $J$. Med. Chem. 49 (2006) 4961-4970.

[2] F.W. Muregi, A. Ishih, Next-generation antimalarial drugs: hybrid molecules as a new strategy in drug design, Drug. Dev. Res. 71 (2010) 20-32.

[3] R. Raj, V. Sharma, M.J. Hopper, N. Patel, D. Hall, L.A. Wrischnik, K.M. Land, V. Kumar, Synthesis and preliminary in vitro activity of mono-and bis-1H-1,2,3-triazole-tethered $\beta$-lactamisatin conjugates against the human protozoal pathogen Trichomonas vaginalis, Med. Chem. Res. 23 (2014) 3671-3680.

[4] B. Meunier, Hybrid molecules with a dual mode of action: dream or reality? Acc. Chem. Res. 41 (2008) 69-77.

[5] R. Fareghi-Alamdari, N. Zekri, F. Mansouri, Enhancement of catalytic activity in the synthesis of 2-amino- $4 \mathrm{H}$-chromene derivatives using both copper- and cobalt-incorporated magnetic ferrite nanoparticles, Res. Chem. Intermed. 43 (2017) 6537-6551.

[6] W.H. Dos-Santos, L.D. Da Silva-Filho, New method for the synthesis of chromeno[4,3b]chromene derivatives via multicomponent reaction promoted by niobium pentachloride, Tetrahedron Lett. 58 (2017) 894-897.

[7] R. Pratap, V.J. Ram. Natural and synthetic chromenes, fused chromenes, and versatility of dihydrobenzo[ $h]$ chromenes in organic synthesis. Chem. Rev. 114 (2014) 10476-10526.

[8] J.A. Tanna, R. Gomaji-Chaudharya, N.V Gandharec, A.R. Rai, S. Yerpuded, D.J. Harjeet, Copper nanoparticles catalysed an efficient one-pot multicomponents synthesis of chromenes derivatives and its antibacterial activity, J. Exp. Nano. Sci. 11 (2016) 884-900.

[9] N.M Sabry, H.M. Mohamed, E.Sh. Khattab, S.S. Motlaq, A.M. El-Agrody, Synthesis of 4Hchromene, coumarin, $12 \mathrm{H}$-chromeno[2,3- $d$ ]pyrimidine derivatives and some of their antimicrobial and cytotoxicity activities, Eur. J. Med. Chem. 46 (2011) 765-772. 
[10] S. Banerjee, J. Wang, S. Pfeffer, D. Ma, L. Pfeffer, S. Pati, W. Li, D. Miller, Design, synthesis and biological evaluation of novel $5 H$-chromenopyridines as potential anti-cancer agents, Molecules 20 (2015) 17152-17165.

[11] G. Zhang, Y. Zhang, J. Yan, R. Chen, S. Wang, Y. Ma, R. Wang, One-pot enantioselective synthesis of functionalized pyranocoumarins and 2-amino-4H-chromenes: discovery of a type of potent antibacterial agent, J. Org. Chem. 77 (2012) 878-888.

[12] J. Ameri Rad, A. Jarrahpour, C.C. Ersanl1, Z. Atioglu, M. Akkurt, E. Turos, Synthesis of some novel indeno[1,2-b]quinoxalin spiro- $\beta$-lactam conjugates, Tetrahedron 73 (2017) 1135-1142.

[13] S. Vandekerckhove, M. D'hooghe, Exploration of aziridine and $\beta$-lactam-based hybrids as both bioactive substances and synthetic intermediates in medicinal chemistry, Bioorg. Med. Chem. 21 (2013) 3643-3647.

[14] T. Sperka, J. Pitlik, P. Bagossi, J. Tozsér, $\beta$-Lactam compounds as apparently uncompetitive inhibitors of HIV-1 protease, Bioorg. Med. Chem. Lett. 15 (2005) 3086-3090.

[15] A. Jarrahpour, S. Rezaei, V. Sinou, C. Latour, J.M. Brunel, Synthesis of some novel 3-spiro monocyclic $\beta$-lactams and their antibacterial and antifungal investigations, Iran. J. Sci. Technol.Trans. A: Science 41 (2017) 337-342.

[16] B.K. Banik, I. Banik, F.F. Becker, Asymmetric synthesis of anticancer $\beta$-lactams via Staudinger reaction: Utilization of chiral ketene from carbohydrate, Eur. J. Med. Chem. 45 (2010) 846-848.

[17] N.M. O’Boyle, M. Carr, L.M. Greene, O. Bergin, S.M. Nathwani, T. McCabe, D.G. Lloyd, D.M. Zisterer, M.J. Meegan, Synthesis and evaluation of azetidinone analogues of combretastatin A-4 as tubulin targeting agents, J. Med. Chem. 53 (2010) 8569-8584.

[18] M. Alborz, A.A Jarrahpour, R. Pournejati, H.R Karbalaei-Heidari, V. Sinou, C. Latour, J.M. Brunel, H. Sharghi, M. Aberi, E. Turos, L. Wojtas, Synthesis and biological evaluation of some novel diastereoselective benzothiazole $\beta$-lactam conjugates, Eur. J. Med. Chem. 143 (2018) 283291.

[19] B. Indrani, F.B. Fredrick, K.B. Bimal, Microwave-induced synthesis of enantiopure $\beta$ lactams, Mod. Chem. Appl. 5 (2017) 2329-6798.

[20] N. Borazjani, A. Jarrahpour, J. Ameri Rad, M. Mohkam, M. Behzadi, Y. Ghasemi, S. Mirzaeinia, H.R. Karbalaei-Heidari, M.M. Ghanbari, G. Batta, E. Turos, Design, synthesis and biological evaluation of some novel diastereoselective $\beta$-lactams bearing 2 -mercaptobenzothiazole and benzoquinoline, Med. Chem. Res. 28, 329-339 (2019).

[21] S.P. Westrip, publCIF: software for editing, validating and formatting crystallographic information files J. Appl. Cryst. 43 (2010) 920-925.

[22] B. Baghernejad, 1,4-Diazabicyclo[2.2.2]octane (DABCO) as a useful catalyst in organic synthesis, Eur. J. Chem. 1 (2010) 54-60. 
[23] J. Wu, X. Sun, Y. Li, DABCO: An efficient organocatalyst in the ring-opening reactions of aziridines with amines or thiols, Eur. J. Org. Chem. 20 (2005) 4271-4275.

[24] N. Razzaghi-Asl, S. Mirzayi, K. Mahnam, S. Sepehri, Identification of COX-2 inhibitors via structure-based virtual screening and molecular dynamics simulation, J. Mol. Graph. Model. 83 (2018) 138-152.

[25] J.N. Sharma, A. Al-Omran, S.S. Parvathy, Role of nitric oxide in inflammatory diseases, Inflammopharmacology. 15 (2007) 252-259. 